Article

\title{
Applying Foresight to Policy Design for a Long-Term Transition to Sustainable Lifestyles
}

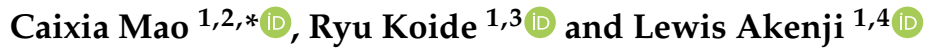 \\ 1 Sustainable Consumption and Production Area, Institute for Global Environmental Strategies, \\ 2108-11 Kamiyamaguchi, Hayama, Kanagawa 240-0115, Japan \\ 2 Institute of International Peace Strategy, Waseda University, 1-6-1, Nishi Waseda, Shinjyuku-ku, \\ Tokyo 169-8050, Japan \\ 3 Center for Material Cycles and Waste Management Research, National Institute for Environmental Studies, \\ 16-2 Onogawa, Tsukuba, Ibaraki 305-8506, Japan; koide.ryu@nies.go.jp \\ 4 Hot or Cool Institute, Manteuffelstrasse 47, 12103 Berlin, Germany; la@hotorcool.org \\ * Correspondence: mao@iges.or.jp
}

Received: 6 June 2020; Accepted: 29 July 2020; Published: 31 July 2020

check for updates

\begin{abstract}
Increasing attention is being paid to lifestyles in sustainability research and policymaking. Applying a foresight approach to sustainable lifestyles supports this increased focus by highlighting possible futures while also empowering citizens through a participatory process. Foresight has its origins in theory and practice to serve the policymaking process by involving diverse stakeholders. In the search to empower various stakeholders in the decision-making process on foresight, this paper analyses the results of a global expert survey to identify factors shaping future lifestyles. Survey results show that in consumption, the reasoning behind increased or reduced consumption matters; in infrastructure, affordability and equal accessibility is a concern; there are some uncertain implications of the changes in work and education, and physical and mental health, which need further exploration in the desired direction. Those factors should be included in public discussions on future sustainable lifestyles through adopting sustainable lifestyles as a foresight topic. Additionally, the survey results on stakeholders' changing roles between now and 2050 illustrate how foresight could empower stakeholders through a bottom-up policymaking approach to realise a long term-transition to sustainable lifestyles.
\end{abstract}

Keywords: policymaking; multi-stakeholder participation; long-term transition; empowerment; sustainable lifestyles

\section{Introduction}

Scholars and policymakers are increasingly paying attention to current ways of living and their impact on sustainability. The Paris Agreement stated the goal for society to transit towards net zero-carbon by the second half of this century, to hold the global average temperature increase well below $2{ }^{\circ} \mathrm{C}$ and pursue efforts to limit it to $1.5{ }^{\circ} \mathrm{C}$ above the pre-industrial levels [1]. Within this context, the Intergovernmental Panel on Climate Change's (IPCC's) special report on the impacts of global warming of $1.5^{\circ} \mathrm{C}$ recognises the changes in human behaviour and lifestyles as enabling conditions for the $1.5{ }^{\circ} \mathrm{C}$ consistent systems transitions' [2]. In Japan's Long-term Strategy under the Paris Agreement, it emphasises "Lifestyles Innovation" for the shift of people's daily living towards long term sustainability [3]. Lifestyle, as an instrument in sustainability, was also included in the Sustainable Development Goals, specifically Target 12.8, which specifies the significance for people to have relevant information and awareness on sustainable lifestyles [4]. Sustainable lifestyles can thus be seen both as an approach to achieve long-term sustainability and as a policy objective to ensure the delivery of high quality of life to citizens. 
In sustainability research, future-oriented thinking is critical due to the scale of change needed: Systemic change instead of minor modifications [5-7]. Among the different sets of approaches in future studies, foresight emerges as an inclusive policy formation process in both theory and practice, to invite non-government stakeholders such as industry and expert groups to participate in giving shape to futures [8]. It is an exercise to create an improved understanding of possible future developments and forces that would be shaped by different stakeholders, in order to search for alternative and desirable futures [9]. Foresight contributes to the decision-making process in three ways: Openness to different futures; involvement of various stakeholders; and policy orientation [10]. Thus, in futures research, compared to the predictive forecasting approach, which focuses on the 'most likely' futures, foresight emphasises a better understanding of futures by looking for the forces that shape them; it is an action-oriented approach to shaping futures in the policymaking process. Considering those features, the foresight process has an instrumental value to improve our understanding of futures for strategy formation, and also an intrinsic value as a democratic participation process to invite more stakeholders such as the general public into the policymaking process towards the desired direction [8].

In terms of government policymaking, foresight's focused topics have changed over time in line with the government's shifting societal concerns [11]. Additionally, future-oriented thinking has long been applied to the environmental field, most notably in the 1972 publication of 'Limits to Growth' and the 1988 establishment of the IPCC [11]. Recent foresight research has extended its search for long-term sustainability into transition studies, adopting more holistic thinking to include social, environmental, and economic aspects [12-14]. Due to the involvement of stakeholders with multiple knowledge fields and organisational background in the process, foresight serves as an interdisciplinary approach to generate knowledge for policy support and crosses administrative boundaries of policymaking areas and ministries [15]. Including the general public in developing a shared desirable future is also pivotal for actors to take actions to move toward a shared vision [12]. However, foresight's potential remains untapped in terms of forming alternative, progressive visions toward long-term sustainability. 'Sustainable lifestyles' as a concept can engage the general public in the policymaking process, allowing individuals to contribute to how policy can support their lifestyle aspirations within environmental limits [8]. In this context, incorporating tools from the field of foresight studies, such as a participatory policymaking process, could facilitate bottom-up policy formulation toward a long-term transition to sustainable lifestyles.

Within this context, this paper proposes key factors that could be incorporated into the participatory process with various stakeholders to envision future sustainable lifestyles. We developed these suggestions based on analysis of an expert survey on daily living and the roles of stakeholders between now and 2050. We also carried out a review of literature in the field of foresight and sustainable lifestyles. While respondents to the survey are experts from various stakeholder organisations rather than citizens, this global survey is unique in that it specifically focuses on sustainable lifestyles and enquires about stakeholders' changing roles. This paper analyses the factors related to shaping future lifestyles based on the changes identified by the expert survey. The interpretation of sustainable lifestyles differs from person to person and from group to group, so instead of offering analysis on the sustainability of the discussed changes of future lifestyles from the survey results, we provide different sets of factors for the public to consider when engaging in discussions on sustainable lifestyles. We analysed the foresighted changes in the roles of different stakeholders to examine whether the current mainstream government-industry-experts approach of any given foresight exercise is enough to discuss the topic of sustainable lifestyles. Moreover, foresight is a policy-oriented exercise, so understanding how stakeholders' roles change is pivotal when taking actions over a long-term transition.

Following this introduction, Section 2 describes the survey's methodology, including its design, data collection, and analysis. Section 3 reviews foresight literature to examine how foresight research and practice contribute to the policymaking process. Section 4 analyses the survey results, focusing on how lifestyles and the roles of stakeholders will change between now and 2050. Based on the analysis 
of the survey results, Section 5 proposes policy formation toward long-term sustainable lifestyles under participatory foresight, and Section 6 concludes by discussing its contribution to this field of research.

\section{Methodology}

\subsection{Overall Methodology}

To analyse changes in daily living and in stakeholders' roles, we first conducted a literature review to determine how the foresight approach could be used in the participatory process to transition to sustainable lifestyles. This review employed an interdisciplinary approach combining foresight studies and sustainable lifestyles research. We aimed to demonstrate how the knowledge gained from these two fields could help empower citizens and other stakeholders to engage in policy formation through a participatory foresight process. Second, we analysed the results of a global expert survey in terms of foresighted changes in daily living between now and 2050 to understand why and how citizens' participation and an intrinsic foresight approach, which empowers citizens in a democratic decision-making process [8], are necessary to better use foresight in policymaking toward sustainable lifestyles. Using the results on foresighted changes in consumption, infrastructure, work and education, and physical and mental well-being, the analysis focused on identifying the determining factors that could shape future sustainable lifestyles to be considered in the public discussions. The survey results show a diverse set of possibilities for future lifestyles and they illustrate how participatory foresight exercises could empower people to engage in the topic of future lifestyles to make tangible changes in their daily living. Third, we analysed how stakeholders would change from two aspects: Their changing roles and their future strengths and positiveness as considered by the respondents in terms of the implications of future sustainability. This analysis was used to derive factors for consideration related to stakeholder participation in the foresight process for future sustainable lifestyles and their potential roles in the transition towards desired futures. Finally, we combined the results of the literature review and survey analysis to propose participatory foresight processes that are useful for envisioning future sustainable lifestyles.

\subsection{The Global Survey and Its Analysis}

This study analysed primary data collected in the Global Foresight Survey of Potential Changes in Society by 2050: Perspectives of Research Institutes and NGOs, which was designed by this paper's authors. The Institute for Global Environmental Strategies and the United Nations Environment Programme jointly implemented the survey between 25 January and 28 February 2018. The free-text survey targeted 1200 authors of selected journals in the field of future studies: Futures (300), Journal of Futures Studies (300), Technological Forecasting and Social Change (300), International Journal of Foresight and Innovation Policy (100), World Futures: The Journal of New Paradigm Research (100), International Journal of Forecasting (50), and Risk Analysis (50). An additional 300 authors were identified through a search of the following keywords on ScienceDirect and JSTOR: 'Foresight Study', 'Foresight 2050', 'Future Foresight', 'Future Scenarios', and 'Futures Studies'. The survey received 137 valid responses, with the valid response rate of about $9 \%$. Based on the online survey software, it showed that each valid respondent spends an average of approximately $30 \mathrm{~min}$ filling out the survey.

Looking at affiliation, $84 \%$ of respondents were from research institutes or universities; $9 \%$ were from non-governmental/not-for-profit organisations, $5 \%$ were from the private sector or consultants, and $2 \%$ were from the government sector. The respondents covered a wide scope of knowledge/expertise. There were more respondents with knowledge on the regions of Europe (55\%) and Asia-Pacific (31\%). A substantial number of respondents were knowledgeable on the remaining regions, including North America (26\%), Africa and the Middle East (20\%), and Latin America and the Caribbean (17\%). A large proportion of respondents either did not focus on specific regions or they focused on the global level $(40 \%)$. For respondents' research and project areas, they covered a wide range of areas, with respondents allowed to select multiple answers: environment (55\% selected this), economy (46\%), energy and 
resource $(43 \%)$, governance (35\%), social policy (33\%), natural science and technology $(30 \%)$, education $(28 \%)$, international development $(21 \%)$, health $(18 \%)$, foreign policy and international affairs $(10 \%)$, defence and national security $(4 \%)$, and others $(32 \%)$. Additional details on the respondents are published in a discussion paper [14].

The survey questions were divided into three parts focusing on changes between now and 2050. Part 1 looked at overall society (culture and social norms, demography, economy, the environment and natural resources, governance structure, and technology and innovation), Part 2 was on the nine domains of lifestyles, and Part 3 focused on the roles of selected stakeholders. The nine domains in Part 2 included five consumption-based domains-food, consumption of manufactured goods, mobility, housing, and leisure [16] —and four non-consumption-based domains measuring people's well-being in terms of work, education, health, and social connections and relationships [17]. In Part 3, the survey provided six stakeholders that are frequently discussed in the literature on sustainability transition: Civil society, governments, households and individuals, local communities, the private sector, and research communities. A comprehensive analysis of the results from Parts 1 and 2 has been published by the authors of this paper [8,14]. This paper focuses on the analysis in Parts 2 and 3.

For this paper, the survey results were analysed using a combination of quantitative and qualitative analysis. The free-text answers on foresighted changes to daily living and stakeholders' roles were first manually labelled by categories of change. To ensure consistency, the given labels were mutually confirmed by two of the authors. Then, the frequency of some labels' presence was summarised in tables for changes in daily living (Sections 4.1.1-4.1.4) and in bar charts for the strengths of stakeholders and the positiveness of futures related to stakeholders' changing roles (Sections 4.2.1 and 4.2.2). Additionally, the foresighted changes in the strengths of stakeholders and positiveness of futures were manually labelled into three levels (stronger, neutral, weaker for strengths; positive, neutral, negative for positiveness) and were cross-analysed and visualised as a mosaic plot (Section 4.2.2). The results of the quantitative analysis were interpreted and supplemented using qualitative analysis, referring to examples of free-text answers from the survey to understand both overall trends and specific context among the survey responses.

\section{Literature Review on Foresight's Role in the Policy Process}

Future-oriented thinking is pivotal to achieve sustainable lifestyles by 2050. Existing scholarly discourse on sustainable lifestyles tends to focus on a consumption-based domain approach, which has the advantage of measuring environmental impacts such as carbon footprint, as demonstrated by [5-7,18]. Analysis of consumption-based environmental impacts or the footprint perspective provides quantitative evidence for progressive policy actions targeting long-term sustainability $[6,19,20]$. However, there is more to a person's lifestyle than just consumption. Aspects of day-to-day life-such as education, work, health, and social connections and relationships-also contribute significantly to determining one's level of well-being [14]. Additionally, emerging trends and disruptive changes in society are likely to shape future lifestyles, such as an increase in displaced populations due to climate change, the role of social networking services in human connections and relationships, and the disruption caused by robotics and artificial intelligence (AI) in employment. These should be incorporated into long-term policy design targeting a transition to sustainable lifestyles $[8,14]$.

Calof and Smith [21] describe foresight's policy impacts include value statements by key actors, foresight's roles in the public arena (such as awareness-raising), project design to meet stakeholder needs, outputs of new knowledge in strategy-making, and policy formulation and delivery. The different phases of foresight—design, implementation, result generation, interpretation, and results and policy formulation-are all vital steps to impact policy [21]. Applying foresight in policymaking has two major areas of value: Instrumental and intrinsic [8]. Earlier foresight research and practices weigh more on the instrumental side, focusing on 'strategic' and 'scientific' aspects and allowing the decision-making process to be supported by scientific knowledge with insights from interdisciplinary experts in policymaking. By contrast and from an intrinsic perspective, foresight enables policymaking to be 
a more democratic process that engages diverse actors such as industry, civil society, and ordinary citizens to influence policy directions before implementation. This inclusive participatory element is important in shaping the decision-making process.

Foresight has been used in different countries for policymaking through government-initiated foresight programmes, particularly on technology and innovation. Such programmes were initiated in the United States and Japan, followed by Western European countries, in the 1990s [22]. Recently, foresight initiatives have been implemented by more countries in different regions; these initiatives have also been initiated by non-government actors, such as United Nations Industrial Development Organization (UNIDO)'s Technology Foresight Initiative in Latin America [23] providing those countries with support on technology and innovation-led policy formulation. Government-led foresight programmes have an advantage in that they are embedded within the government agencies and, thus, directly feed into the policy process. However, agenda-setting on foresight also tends to be determined by government interests - such as national security $[15,24]$ or technology and innovation in industries [25]—instead of topics that are more relevant to ordinary citizens' lifestyles. Moreover, the stakeholders involved tend to be experts, industry representatives, and policymakers without the involvement of the general public. The public is generally only informed through outreach programmes communicating the foresight outcomes [26]. Thus, the general public and other key actors are often underrepresented in the process despite foresight's enormous potential effect on them [25]. It has also been argued that those setting the agenda on foresight tend to shape the research results and development agenda [27], limiting the discourse on futures to a predetermined framework [28]. In such a setting, foresight serves as an instrument for those actors to reach a consensus rather than being applied to search for alternatives [29].

Addressing the shortcomings in government-led foresight requires that more stakeholders, including the general public, be invited to discuss futures, thereby ensuring the empowerment of citizens [28,30-32]. Citizen participatory foresight is particularly significant in the search for long-term sustainability, which requires systemic structural changes. In this approach, foresight's intrinsic aspect of empowerment to serve the democratic decision-making process is more valuable than its strategic aspect. Inviting marginalised stakeholders or citizens into the foresight process shifts the discourse when setting the agenda, ensures that foresight's proposed policy solutions include 'fundamental changes in the system' [28], and involves these actors to engage and shape the future they want [33]. In this way, foresight is well placed to empower underrepresented actors in the policymaking process [29] using topics that are tangible and familiar to their lifestyles and extending these topics to broader socioeconomic issues surrounding these individuals [13]. Consequently, adopting the concept of 'sustainable lifestyles' in participatory foresight could open the discussion to revisit public policymaking as a method to improve people's quality of life and to empower the public to become agents shaping their own lifestyles through foresight. In this context, this research aims to contribute to participatory foresight in the topic of sustainable lifestyles from two aspects: To analyse the foresighted changes in daily living to understand weaknesses in the current mainstream approach of foresight; and to generate increased understanding on the changing roles of stakeholders in future society. This should be taken into consideration when looking at stakeholder involvement for foresight exercises and when forming collective actions towards shared sustainable lifestyles.

\section{Survey Result and Analysis}

In terms of policy formation through the participatory foresight process to transition to long-term sustainability, our analysis of the survey results focused on two elements: (1) Determining factors in shaping future lifestyles from four aspects (consumption, infrastructure, work and education, and physical and mental health); and (2) the changing roles of different stakeholders (governments, the private sector, research communities, civil society, local communities, and households and individuals). Among the four aspects of future lifestyles, there are 258 changes reported in total with the following distributions as illustrated in Figure 1: 53 in consumption (32 in food, 21 in manufactured 
goods), 44 in infrastructure (36 in mobility, 8 in housing), 77 in work and education (47 in work, 30 in education), and 71 in physical and mental health ( 38 in health, 25 in social connection and relationships, 8 in leisure). There were 13 responses reported as other domains that are excluded from this analysis. The results and analysis in this section supplement the current discourse on sustainable lifestyles and foresight studies, providing directions for policy formation for the long-term transition to sustainable lifestyles. A more detailed analysis of the survey results related to the foresighted changes in society and daily living between now and 2050 has been published as a discussion paper [14], and analysis focused on the technology aspect of foresight has been published in a research article [8].

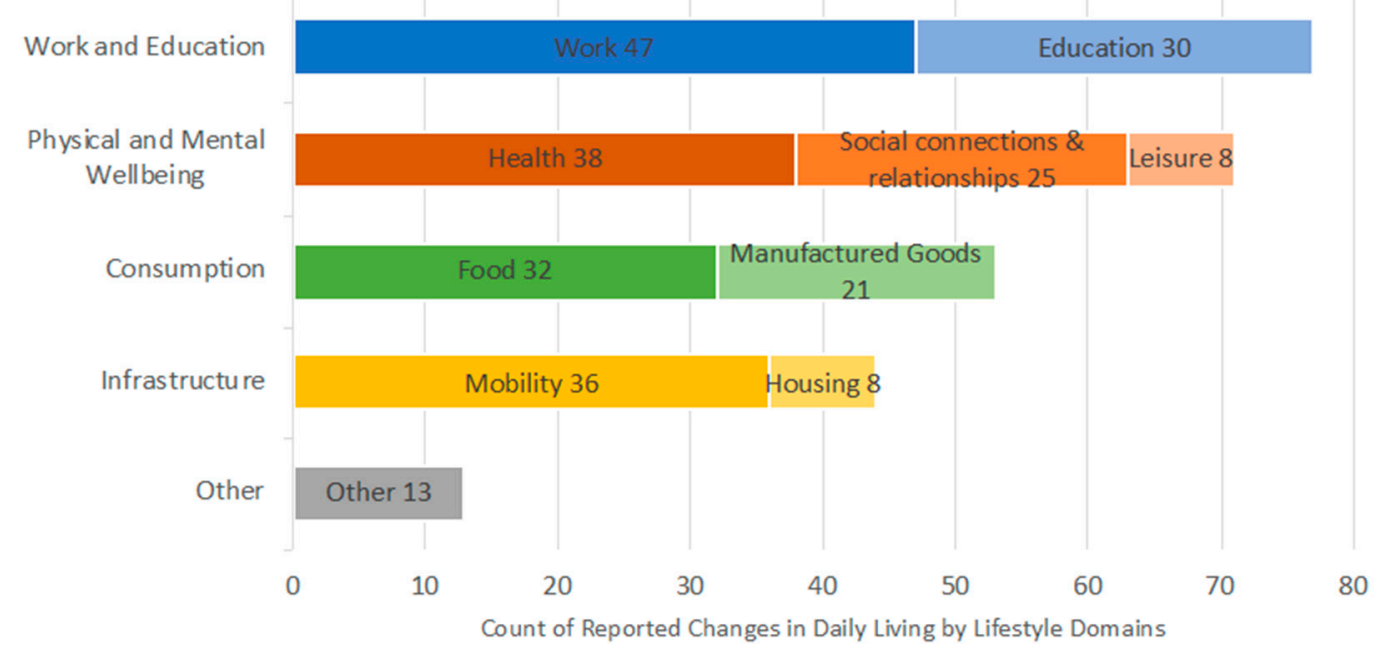

Figure 1. Lifestyles domains in daily living selected by the respondents. Notes: Lifestyle domains in daily living selected by the respondents in the Global Foresight Survey of Potential Changes in Society by 2050: Perspectives of Research Institutes and NGOs. Numbers are counts of valid responses. Percentages are the share in total responses. Valid responses only. $\mathrm{N}=258$.

\subsection{Changes in Four Aspects of Lifestyle}

\subsubsection{Consumption}

Thirty-two of the 258 total changes reported in Part 2 of the survey are related to food, with responses focused on three areas: Dietary habits, food security, and location of production (see Table 1). For dietary habits, the respondents described changes to the drivers of diet in terms of voluntary and forced change. Voluntary change is due to increased health and environmental concerns and to the preference for convenience in food, whereas forced change is because of food scarcity and the environmental necessity to reduce food's impact on the environment. In terms of food security, results covered factors that could see an increase in both food production and food scarcity. As pointed out by the survey respondents, one major element that could increase food production is technological innovation, although the effects of climate change and population growth are likely to outstrip any productivity increase and would result in food scarcity. For location of production, there were views that both local production and global production would increase, with localised food production likely to occur in urban areas for self-sufficient food production. There were also views that global-scale food exports and imports will account for a large portion of the economy.

Manufactured goods comprised 21 of the 258 reported changes, with results covering both demand shift and sharing and production patterns (see Table 1). For demand shift and sharing, the results show a likely shift from mass consumption to reduced demand for goods due to the increased adoption of the 3Rs (repair, reuse, and recycle), especially in current high-income countries. However, it was also noted that there would be a rise in consumption due to the increasing middle class in emerging economies. Production patterns included two major trends: Localised and smaller-scale 
production by local producers and environmentally friendly production, such as replacing crude oil with algae-based fuel and using biodegradable materials instead of oil-derived plastics.

Table 1. Changes in consumption.

\begin{tabular}{l}
\hline \multicolumn{1}{c}{ Consumption } \\
\hline Food \\
Dietary habits: vegetarian (12), health concern (9), insect-based food (6), artificial meat (5), convenient food (5), \\
environmental concern (5), fish/aquaculture (4), white meat (3), restriction/less variation (3), polarisation of \\
dietary habits (3), organic food (2), vegan (2) \\
Food security: food scarcity (6), reduced food waste (3), use of Information and Communications Technology \\
(ICT) (2), supply chain productivity (2) \\
Location of production: local production (6), global production (3), urban farming (3)
\end{tabular}

Manufactured Goods

Demand shift and sharing: repair/reuse/recycle (8), less consumption of goods (6), sharing/servitisation (4), more consumption of goods (3), experience-based consumption (3), more waste (2), less waste (2)

Production pattern: localised/small-scale production (7), environmentally-friendly design/production (4),

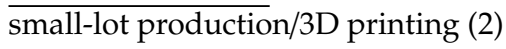

Notes: Consumption changes were mentioned as part of the changes in daily living from the Global Foresight Survey of Potential Changes in Society by 2050: Perspectives of Research Institutes and NGOs. Multiple labels were allowed per response, and the frequency of counts is in parentheses. The unit of analysis is reported changes in daily living, and each respondent could report up to two changes. $\mathrm{N}=53$.

\subsubsection{Infrastructure}

Mobility received a high level of responses, 36, with the discussion focused on access and demand, mobility technology, and transportation mode (see Table 2). For access and demand, there were views on reduced mobility demand due to digital transformation through video conferencing, teleworking, and labour platforms. Respondents also mentioned the drivers of increased mobility demand due to globalisation, conflict, and climate change. Although technological development would result in lower mobility costs, there are also concerns over unequal access to this technology based on affordability. The dominant change in mobility technology appears to be in automated vehicles, with electric/hybrid vehicles likely to have a larger share of the automobile market due to increased regulations on vehicles using fossil fuels. Other technology such as high-speed transport will also increase. In transportation mode, there were reported changes in considering mobility as a service for sharing, and people use public transport more often which results in fewer cars.

Table 2. Changes in infrastructure.

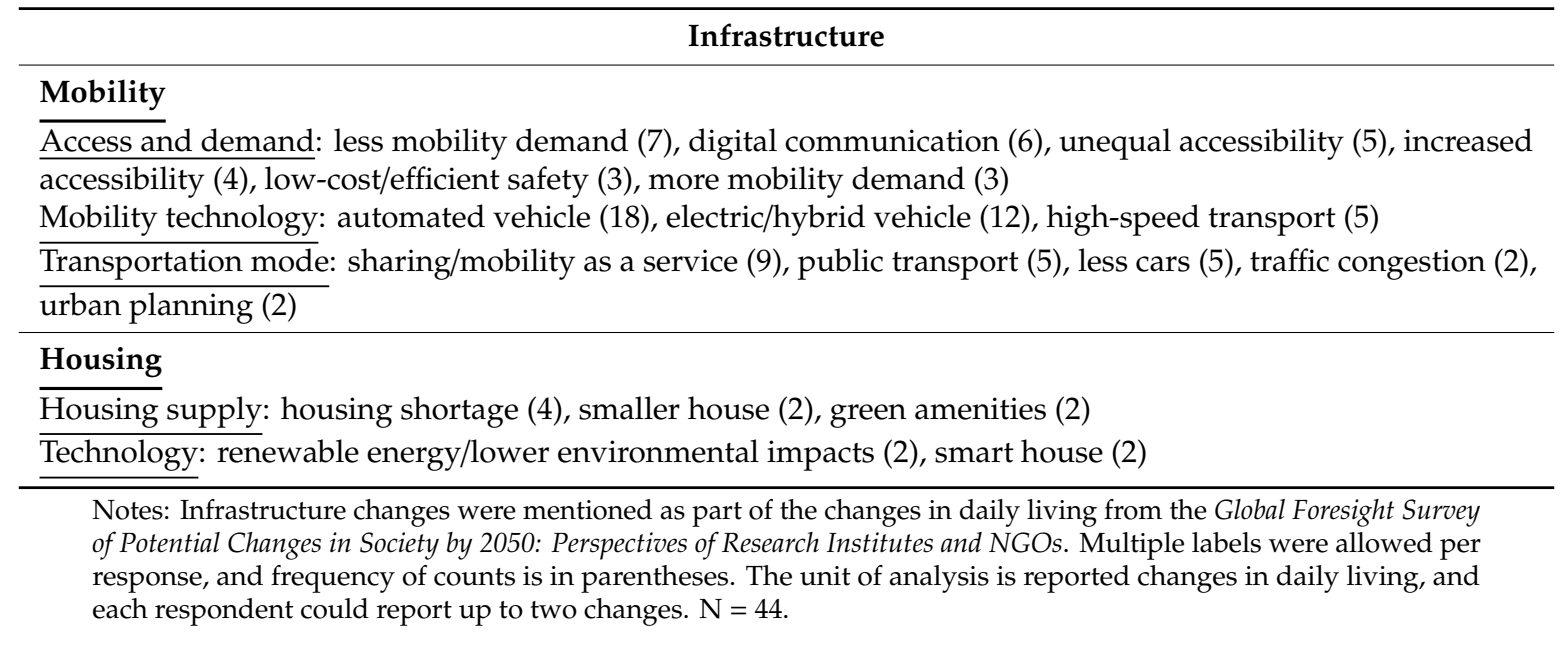


The housing domain had only eight responses, and the discussion focused on housing supply and technology (see Table 2). In housing supply, a housing shortage due to climate change and rapid urbanisation would result in people shifting to smaller homes; housing would also incorporate green amenities in response to climate change. In technology, houses will likely incorporate the latest environmental technology and become 'smart homes', but again, technological innovation in housing will only be available those who can afford it.

\subsubsection{Work and Education}

Work is the domain that received the most responses-47 of 258-and responses focused on three areas: Labour market, format of work, and meaning of work (see Table 3). For the labour market, one key change is the replacement of human labour by AI, robotics, and automation, which will likely cause significant unemployment alongside changes to the labour market involving a demand for irreplaceable highly skilled and new-skilled jobs, as well as service- and human-centred jobs. The labour market itself will become more fluid, and permanent employment is likely to disappear. There were also responses on increased job opportunities from a sharing economy, with the labour market itself becoming more globalised. In terms of format of work, communication technology would offer new work formats such as remote work. In addition, the work itself would be more flexible, with more people freelancing or working fewer hours through work-sharing for a better work-life balance. For meaning of work, people's perceptions on meaning would also shift due to a changing labour market. This market would also require a new remuneration system, such as universal basic income, so individuals could have more leisure time and seek new means of fulfilment. Inequality is also likely to grow with less social security due to structural unemployment.

Table 3. Changes in work and education.

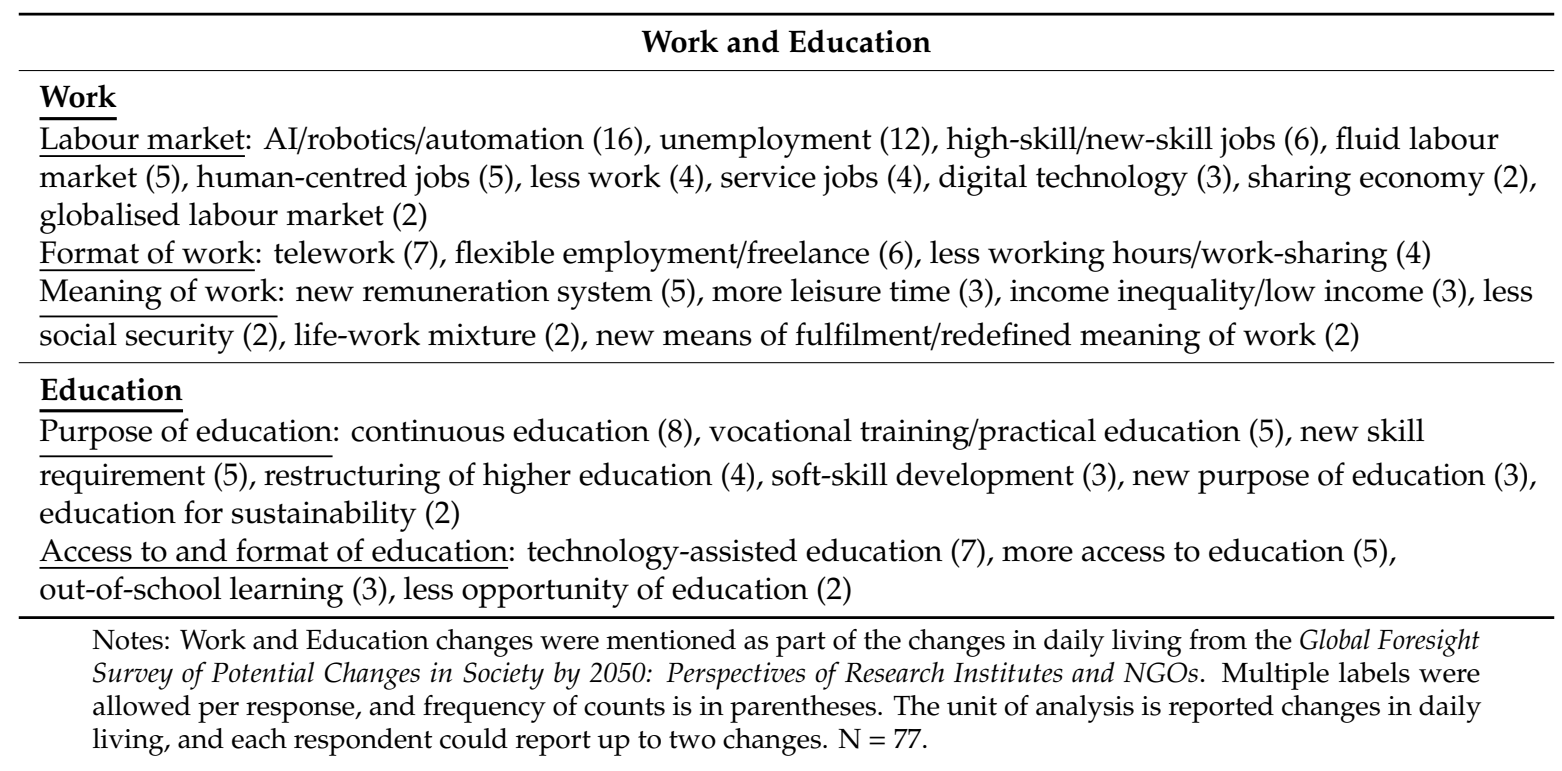

Thirty of the 258 responses focused on education, namely on the purpose of education, as well as access to and format of education (see Table 3). Looking at the purpose of education, people might continue their education throughout their life to update their skills in a society rapidly changing due to technological disruptions. Furthermore, education's purpose might shift to prevent mental degradation and a sense of irrelevance when mass human labour is replaced by robotics and machine learning. The content of education would also change, with more vocational training, practical education, soft-skill development, and education for sustainability. For access to and format of education, technology's role will increase the use of online education, interactive education via computers, and earlier education on computer science. Access to education may well increase through digital 
means, but there were also views that educational opportunities might be limited to specific groups despite improvements in education technology.

\subsubsection{Physical and Mental Health}

Eight responses were related to leisure, specifically on the format and purpose of leisure (see Table 4). Respondents indicated that there would be more experience-based leisure such as holidays and green tourism. Technology development will also provide leisure using virtual reality and artificial leisure, although unequal accessibility would be a concern. There were also views that people could have more leisure time due to the replacement of human labour with robotics and AI.

Table 4. Changes in physical and mental health.

\begin{tabular}{l}
\hline \multicolumn{1}{c}{ Physical and Mental Health } \\
\hline$\frac{\text { Leisure }}{\text { Format and purpose: experience-based leisure/self-realisation (4), unequal accessibility (3), more leisure time }}$ \\
\hline (2), virtual reality/artificial leisure (2)
\end{tabular}
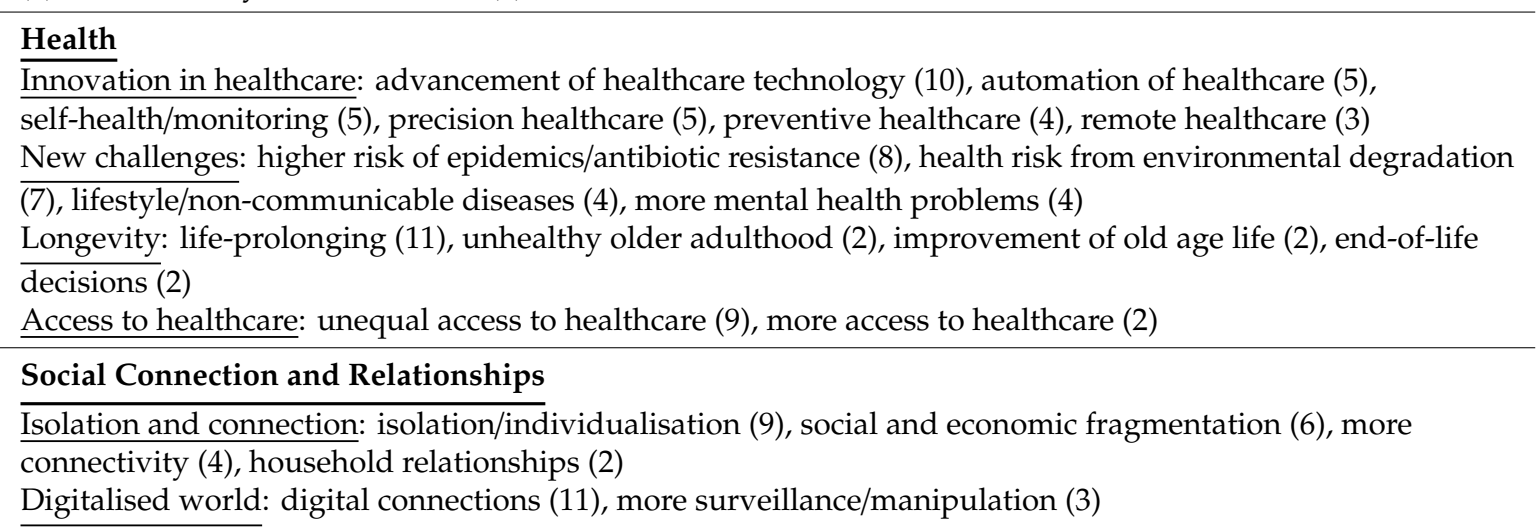

Notes: Physical and mental health changes were mentioned as part of the changes in daily living from the Global Foresight Survey of Potential Changes in Society by 2050: Perspectives of Research Institutes and NGOs. Multiple labels were allowed per response, and frequency of counts is in parentheses. The unit of analysis is reported changes in daily living, and each respondent could report up to two changes. $\mathrm{N}=71$.

Thirty-eight responses focused on health, covering four areas: Innovation in healthcare, new challenges, longevity, and access to healthcare (see Table 4). For innovation in healthcare, technological advancement would bring innovation to healthcare, which might involve developing more effective treatments of some diseases such as cancer and Alzheimer's disease. Due to the high cost, healthcare will likely only be accessible to those who could afford it. The application of massive datasets will also be common for automated diagnosis and remote healthcare, and healthcare will be more personalised, with self-monitoring, precision medicine, and preventive care. Some new challenges were also raised, such as antibiotic resistance, diseases from environmental degradation, lifestyle diseases, and mental diseases. For longevity, advances in healthcare technology will mean people living longer but will also cause longer morbidity periods and unhealthy older age, leading to the need to consider end-of-life decisions involving assisted suicide. There were also views that due to increased health concerns, there will be improvements the quality of life for older adults. In terms of access to healthcare, the view is that access to healthcare would remain unequal in spite of technology advancement. There were also responses on the emergence of private entities that might make healthcare more accessible in innovative ways.

Twenty-five responses focused on social connection and relationships, specifically on isolation and connection and on the digitalised world (see Table 4). In terms of isolation and connection, there were views that people would be more isolated due to the spread of Western lifestyles and, thus, people would focus more on self-improvement and individual lifestyle. Other factors include fewer marriages, more divorces, smaller families, digital communication, and more individualised 
leisure pursuits. Responses citing more connection are supported by the fact that people would return to their extended families due to ageing demographics, more time for social networking due to less work, and globalisation leading to more tolerance for diversity. There were also responses on changing perceptions of gender due to women's empowerment. For digitalised world, social interactions are more likely to take place online, with reduced attention spans and less intimacy. There were also views that online connections might collapse, and people would return to face-to-face communication. Due to increased online communication, there were also concerns about greater surveillance and manipulation by using big data to control people's behaviour.

\subsubsection{Determining Factors on Shaping Future Sustainable Lifestyles}

Based on the survey results, we derived several determining factors in shaping future lifestyles for each aspect of lifestyle. For consumption, respondents discussed reducing the level of consumption of food (meat) and manufactured goods, but with different rationales depending on the group: For some, it would be due to scarcity of resources, while for others, it would be to fulfil their values on health and the environment. According to research using quantitative analysis to determine the required level of consumption to achieve long-term sustainability [34], these survey results add value to the discussion in the form of various drivers underlying the changes in consumption level.

In terms of infrastructure, technological advancement appears to be an important factor in providing more choices, although respondents noted affordability and equal accessibility as concerns. Thus, technological improvement-and the implication that it could fulfil people's pursuit of a meaningful life-requires additional research [8]. Changes in work and education are disruptive due to technological innovation, meaning they require engaging the general public in a more comprehensive assessment of the desired direction [35]. In terms of physical and mental health, uncertainties remain regarding mental health's effects on people's lifestyles, such as on whether longevity contributes to a more active later life and on whether digitalisation would contribute to more meaningful connections or result in more isolation.

The interpretations on sustainable lifestyles are diverse and non-static, and the respondents of the survey provided a diverse set of possibilities in how the future lifestyles could change. Thus, based on the individuals' interpretation of their desirable future lifestyles, discussions on whether foresight future changes in lifestyles are sustainable or not could be included in the public discussion on the participatory foresight process.

\subsection{Stakeholder Roles}

\subsubsection{The Strength of Different Stakeholders' Roles}

Based on the free-text responses, Figure 2 depicts the changing strength of different stakeholders between now and 2050. Government (national governments) is the only stakeholder whose power is perceived by respondents as neutral or weaker. Of those responding on government, $25 \%$ think its role will be stronger than today, compared to $29 \%$ who provided neutral responses and $46 \%$ who think its role will be weakened. A major factor raised by the respondents saying the government's role will be stronger was the belief that government will impose greater control and regulations on society, people, and companies. Those selecting neutral said government's structure will be more decentralised and interactive through direct democracy. Those selecting weaker provided reasons such as reduced public trust in politicians, reduced need for politicians since people could more easily reach consensus using digital platforms, government's inability to handle the challenges caused by climate change and a rapidly changing society, and the independence of central entities from nation-states.

The majority of respondents $(74 \%)$ believe the role of the private sector will be stronger due to increased privatisation of social services, the private sector's potential role in the common good or in society's destruction, and mega-corporations increased influence on government policies. Seventeen per cent of respondents consider the private sector's role to be neutral, mentioning changes in its 
production process and working models, and $9 \%$ believe it will be weaker due to regulations and the redistribution of capital to the government, civil society, and customers.

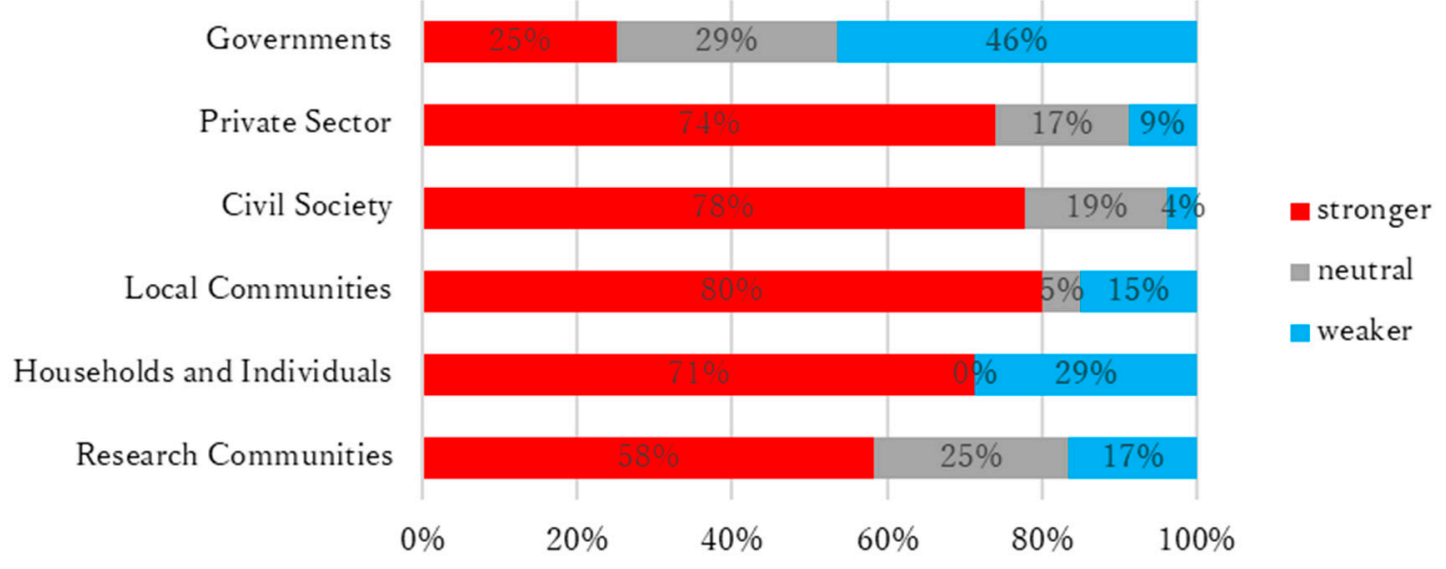

Figure 2. Respondents' projected changes to stakeholders' strength. Notes: the share of the strengths of stakeholders described in the responses of changes in stakeholders' roles in the Global Foresight Survey of Potential Changes in Society by 2050: Perspectives of Research Institutes and NGOs. The unit of analysis is reported changes in stakeholders' roles. $\mathrm{N}=124$.

For research communities, $58 \%$ of respondents think these communities' role will be stronger due to increasing global complexities. Responses also indicated that different stakeholders are likely to value the knowledge produced by researchers, who would thus have a larger role in the decision-making process. Twenty-five per cent of respondents provided a neutral response, while $17 \%$ said researchers' role would be weaker due to a shift from research to consultancy work and due to decreased respect for science due to the overflow of information available online.

Civil society, local communities, and households and individuals represent stakeholders at the grassroots level, although there are some overlaps in the classifications of the three groups. Depending on assumptions, local communities, households, and individuals are part of civil society, which could gain the power to act against other stakeholders that are traditionally included in foresight exercises such as the government and private sector [14]. The topic of sustainable lifestyles covers many tangible aspects of daily living and require local communities at the municipal and community levels to provide infrastructure for necessary collective actions [16]. Households and individuals are required make lifestyles decisions and become vital actors in the participatory foresight process. Thus, the distinctions between the three sets of actors are made in this study.

Seventy-eight per cent of respondents who selected civil society indicated that its role will be stronger. Civil society is considered a leader in social change through social movements, self-organisation to build large networks through technological platforms, and greater activity in the policy process and service provision; civil society also acts to counter the power balance with the private sector and fills power vacuums created by a weakened government. Those empowering civil society will act at both the local and global level. Nineteen per cent of responses were neutral, mainly because respondents were unsure whether civil society would be stronger or weaker in the future, and $4 \%$ said civil society will be weakened due to the increasing influence of large corporations.

As with civil society, the vast majority of respondents $(80 \%)$ said local communities will have a stronger role due to stronger supportive and inclusive networks developed at the community level for local needs such as local production and consumption. Advances in communication technology will also likely enable people to collectively influence national policies. These changes will probably fill the gaps and bridge the inability of services and governance that only rely on the government. Five per cent of respondents were neutral, and $15 \%$ said that local communities would be weaker due to 
young people becoming more detached from the real world, the loss of a sense of community, and the impoverishment of local communities due to urbanisation.

For households and individuals, $71 \%$ of respondents said that this group would be stronger due to the improvement of communication technology for information-sharing and that it would be more independent due to the home production of goods and services. As consumers, households and individuals would also demand more sustainable products. Conversely, $29 \%$ think these actors would become weaker due to structural unemployment and increased inequality, loss of power to corporations and a wealthy minority, and lack of concern for the real world because of increased attention to the virtual world.

\subsubsection{Cross-Analysis of the Strengths and Positiveness in Stakeholder Roles}

Considering the importance of stakeholders' role in the participatory foresight process, we also conducted a cross-analysis of the strength and positiveness in their changing roles by respondents. For instance, the response below illustrates that local communities will have a stronger role, and this is considered to be positive to the society's sustainability by the respondent:

"Local communities will be more supportive of equity and inclusion, being more integrated socially, economically, and racially; communities will be supportive of co-production of many needs, and of trading/exchanging goods and services internally; they will with their governments and utilities evolve the energy grid to enable in-home and in-community production and storage; they will be more caring for all in the community, supporting the opportunities for all to contribute, grow in meaning and thrive."

Another example below shows that households are getting weaker, and this is considered to be negative to the society's sustainability by the respondent:

"Individuals are losing ground on several counts—corporate rights are stronger, ability for individuals to fight the system are eroding; taxes favor wealthy and corporations; unions are weakening, as are worker rights."

Figure 3 depicts the positiveness of the foresighted future related to stakeholders' changing roles, and Figure 4 depicts the cross-analysis on strength and positiveness.

In terms of the positiveness of the foresighted future related to stakeholders' changing roles, the majority of those who selected governments, the private sector, and research communities selected neutral, which implies that these actors' role could move in either direction. For civil society and local communities, responses were more positive (48\% and $60 \%$, respectively). Responses for households and individuals were well-distributed: $29 \%$ positive, $36 \%$ neutral, and $36 \%$ negative.

The results of the cross-analysis on the strengths and positiveness of the changing roles of each stakeholder (see Figure 4) demonstrate that there are variable implications for different stakeholders. For government, the majority of respondents consider a stronger role to be positive and a weakened role to be negative, meaning government's role should be stronger for a positive future. For the private sector, most respondents selected a stronger role, but its positiveness implication is more 'neutral'; this implies that the private sector's strengthened role could be either positive or negative in the future. A weakened role for the research community was considered negative, meaning these communities should be strengthened for a positive outcome.

Most respondents indicated that civil society should have a stronger role, although responses on positiveness were divided between positive and neutral. Nevertheless, this was a negative outcome for those who did not feel civil society would be stronger. Additionally, although most respondents said local communities' role would be stronger, some gave a neutral response, and positiveness was divided among positive, neutral, and negative; this implies that uncertainty exists with regards to the future direction of this stakeholder group. For households and individuals, although the majority 
felt this group's role would be stronger, some felt its role would be neutral. Nevertheless, weakened households and individuals were considered negative.

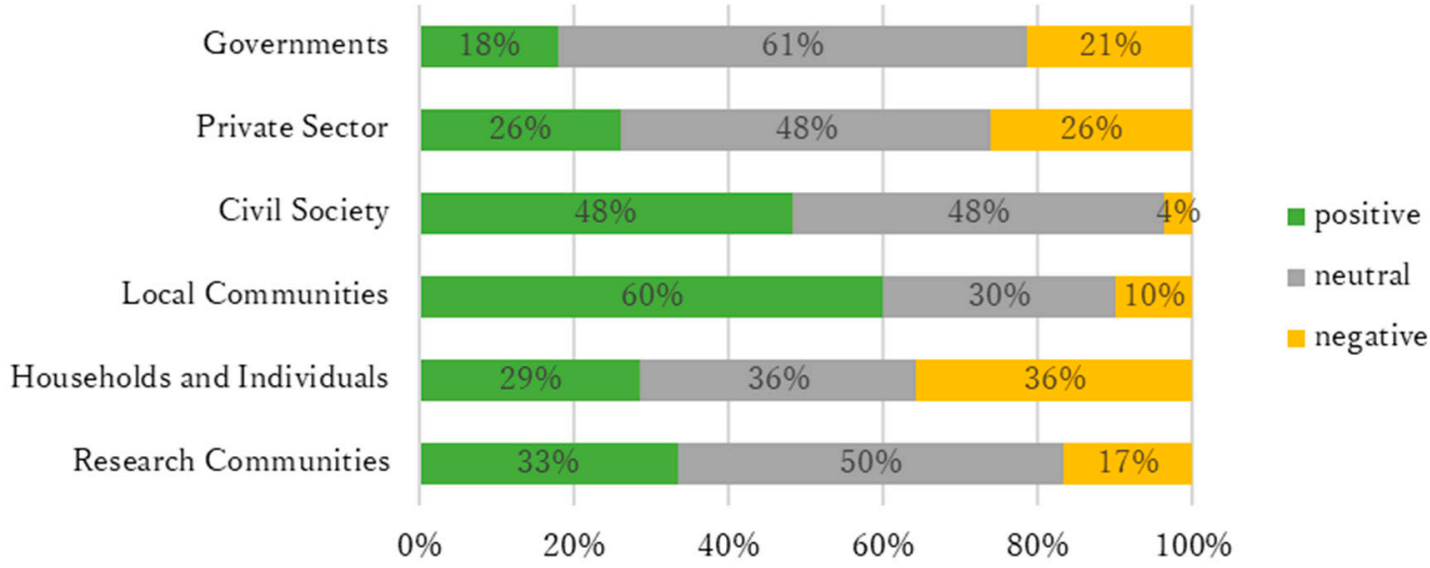

Figure 3. Positiveness of the foresighted future related to stakeholders' changing roles. Notes: the share of the positiveness of future described in the responses of changes in stakeholders' roles in the Global Foresight Survey of Potential Changes in Society by 2050: Perspectives of Research Institutes and NGOs. The unit of analysis is reported changes in stakeholders' roles. $\mathrm{N}=124$.

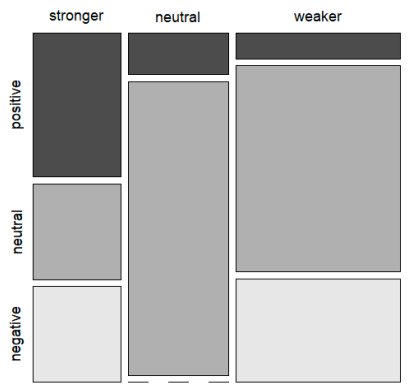

(a) Governments.

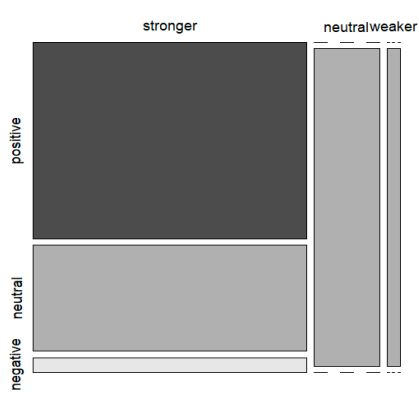

(d) Civil Society

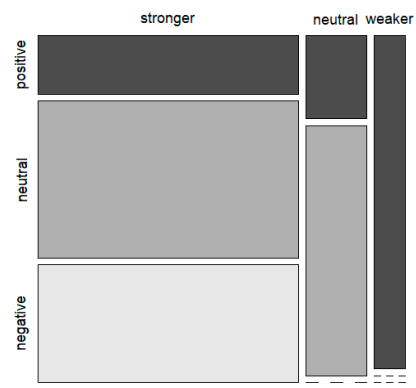

(b) Private Sector

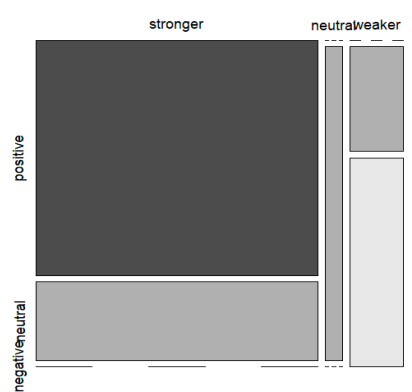

(e) Local Communities

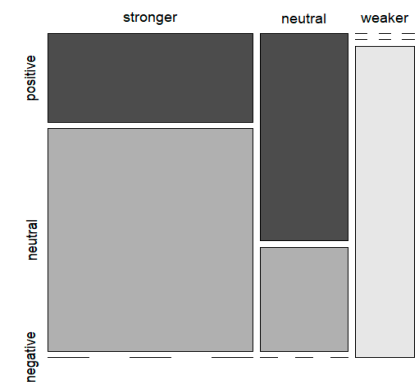

(c) Research Communities

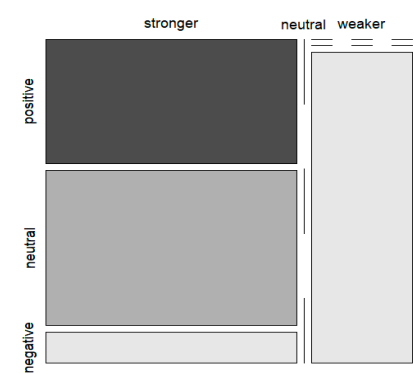

(f) Households \& Individuals

Figure 4. Cross-analysis of the strength and positiveness of stakeholders' changing roles. Notes: mosaic plots of the strengths of the stakeholder and the positiveness of the future described in the responses of changes in stakeholders' roles in the Global Foresight Survey of Potential Changes in Society by 2050: Perspectives of Research Institutes and NGOs. Horizontal axis refers to the strengths of stakeholders. Vertical axis refers to the positiveness of future. The size of boxes refers to the number of responses belongs to each combination of strength and positiveness. The unit of analysis is reported changes in stakeholders' roles. $\mathrm{N}=124$. 


\subsubsection{Stakeholders' Changing Roles}

The results on stakeholders' changing roles between now and 2050 indicate that the government's role could be weaker in the future. More actors at the grassroots level—such as civil society, local communities, and households and individuals—are expected to increase their roles and positively change society. Thus, in foresight design, relying on a government-led process is no longer efficient when other essential stakeholders from the grassroots level are missing. Although not perceived positively when having a stronger role, the private sector was found to be pivotal in shaping futures both positively and negatively. Thus, engaging the private sector in the foresight process could provide a foundation to involve it in discussions on transitioning to a desirable future. For research communities, foresight experts have been key actors in government-led foresight, and the role of research is likely to remain vital, involving different actors and facilitating their future-oriented thinking in the foresight process. Currently, foresight serves to inform policymakers mostly based on expert knowledge, but this must be expanded to gather the general public's collective knowledge and to empower individuals to shape policies for the desired long-term transition.

\section{Policy Formation toward Long-Term Sustainable Lifestyles under Participatory Foresight}

This analysis of the survey results makes an important contribution to discussions on policy formation towards long-term sustainable lifestyles through participatory foresight in two aspects.

(1) Changes in the future lifestyles discussed in the survey results revealed that bi-polar changes were foresighted: How to evaluate these changes is a matter of various values and context among people, so we need the participation of households and the local community in the foresight. We could confirm that various changes were expected in daily living, which are beyond technology and macro-level changes. Thus, participation of households and local community is necessary to apply foresight on the lifestyle topic. Based on different sets of interpretations of sustainable lifestyles, foresight exercises could look at the diverse possibilities of change in lifestyles mentioned in the survey and discuss which of these is desirable and which should be avoided. This could be seen as a democratic process to decide the goal of the policymaking in achieving desirable lifestyles. For consumption, although it is easy to simply measure how much consumption levels have increased or decreased, the survey results pointed out that it is the reasoning behind increased or reduced consumption that matters when it comes to understanding whether the choices are forced or voluntary. In infrastructure, technology advancement would likely increase the options. However, there needs to be more scrutiny of these issues in terms of affordability and equal accessibility to advanced choices. In the areas of work and education, the implication of potential disruptive changes brought by robotics and automation is not yet clear. The impact of prolonged life brought by medical advancement and digital connection to mental health should be better investigated depending on different people's aspirations.

(2) The changing roles of stakeholders in the survey should be considered when designing foresight exercises for stakeholder inclusions and their roles to achieve foresighted futures. In addition to government, private sector, and the experts in the conventional foresight exercises, the survey results show there are more stakeholders at the grassroots level of societies. The potential change in those stakeholder roles should be considered so that the whole of society can transition towards sustainable futures. The survey results show that the role of government will weaken, so long-term transition requires other stakeholders that are conventionally ignored in foresight exercises at the grassroots level. These include civil society, which would come under consideration to lead social movements, as well as local communities that provide the base for local production and consumption, and individuals and households that could be strengthened through collective power.

Foresight should not be limited to the future of technology, as is commonly the case; it should also be used to understand and shape societal expectations and more nuanced areas such as value systems, 
which tend to shape norms and lifestyle choices. Policy processes designed to benefit from the foresight approach should contribute to the decision-making process by involving various stakeholders and maintaining an openness to a variety of possible futures [10]. Such openness and wider participation would give policy more legitimacy, and thus lead to greater uptake and more effective implementation. However, to be successful, policy processes enabled by foresight would need to be grounded in science-based information, supported by stakeholder education on issues and risks needing to be addressed, and led through a well-facilitated process. Moreover, ongoing efforts to discuss people's lifestyles in foresight exercises are mostly being carried out in European countries [13,31], whereas this survey provides a more global context on this topic.

This paper has provided examples of involving different stakeholders in the participatory foresight process to illustrate factors to consider in the future development of policies on the long-term sustainability of lifestyles. The benefits of foresight in policymaking could have both instrumental value in a more informed decision-making process and also intrinsic value through empowering citizens in a participatory policymaking process [8]. However, a major challenge in future foresight design is how to engage with different stakeholders in the foresight process when the speed of change is increasing due to technological disruption and the interconnectedness of the global system. The current period of uncertainty also provides opportunities to move in a more sustainable direction, with the recent outbreak of Coronavirus Disease 2019 (COVID-19) resulting in destructive changes to society during lockdowns that have impacted people's employment, mobility, leisure, and mental well-being. Many of the possibilities discussed in the expert survey provide determining factors to move forward, such as the discussion on universal basic income and the implications of the rapid digitalisation of people's lives for privacy. Although COVID-19's long-term sustainability implications for society and for people's lives require greater scrutiny and discussion, the destructive changes provide a space to boldly reimagine different futures, especially among those who have the agency in democratic societies. Rather than waiting with anxiety and passiveness, applying a participatory foresight mindset means that inventing a new future - not merely extending business as usual—could be the way forward.

When looking at instrumental values, Slaughter (1995) [36] considers foresight to be 'a process that attempts to broaden the boundaries of perceptions in four ways: By assessing the implications of present actions, decisions, etc. (consequent assessment); by detecting and avoiding problems before they occur (early warning and guidance); by considering the present implications of possible future events (proactive future formulation); and by envisioning aspects of desired futures (normative scenarios).' Instrumental or more strategic aspects [8] of contributions from this research in the field of foresight demonstrate that there have been changes to different aspects of future lifestyles and to stakeholders' roles. The survey results discussed here illustrate that the determining factors extend beyond a domain-based approach to lifestyles, which could facilitate more holistic and systemic views when engaging stakeholders in foresight discussions. One cross-cutting trend is the polarisation of those who will have more options as technology advances and those who will likely be deprived and marginalised due to increasing inequity. Moreover, even for individuals with more options, the implications of a 'better quality' of life are complex and require discussion with the general public.

From an intrinsic perspective [8], there are limitations to engaging 'non-expert' groups such as citizens in this process. Insights into stakeholders' changing role demonstrate that greater engagement with stakeholders from local communities, civil society, and households and individuals could empower them and lead to positive changes for society. Meanwhile, the roles of government, the private sector, and research communities have the potential to move in either a positive or negative direction in the future. Interestingly, the survey results indicate the private sector has the potential to make a transition to be more-or less-sustainable. As the private sector is a key stakeholder, its involvement and cooperation with other stakeholders should be more strongly facilitated in the participatory foresight process.

Due to the potentially increasing role of grassroots-level stakeholders, a foresight process with a more bottom-up approach feeding into policy design could mean a more inclusive policy process. Such 
opportunities should be used in engaging stakeholders in foresight design. However, when focusing on future lifestyles, it is even more relevant and tangible for citizens to be part of the policy-formation process. In fact, even a bottom-up foresight process is normally facilitated by experts in the foresight field who then engage the general public to discuss their futures [13,31]; thus, more collaboration among experts and grassroots-level stakeholders could empower both sets of stakeholders. Due to the perceived declining strength of government in the survey results, engaging other stakeholders in policymaking would not only ensure a more inclusive process to better reflect the needs of all stakeholders but also delegate some of the government's roles to other stakeholders as a part of their democratic participation.

\section{Conclusions}

Foresight has been serving the policymaking process by engaging experts and different stakeholders to put expert knowledge into action. However, foresight has clear, untapped potential to empower the general public to become involved. Positioning foresight to address lifestyles opens up discussions that could be relevant to the general public, thereby influencing policymaking in tangible ways. To date, government, the private sector, and research communities have been involved in the discourse on foresight. Now, it is time for more actors at the grassroots level—such as civil society, local communities, and households and individuals-to be considered in the process. In particular when sustainable lifestyles become the focus of the foresight exercise, civil society could be the actor to gain power in society to counter the underlying assumptions that it is government and industry which take the lead in conventional foresight. Local communities have the potential to mobilise collective actions to assert their local needs in providing enabling conditions for sustainable lifestyles. Lastly, households and individuals should pursue their own desirable future lifestyles by engaging in the formation of future policy decisions as part of the democratic participation process.

Foresight and participatory policymaking processes are especially important in areas such as food, social connections, and relationships, which are less driven by expert knowledge and more affected by perceptions and societal norms. Policy on the future of food consumption (and thus, production) is not just an issue of the technical production and distribution of food; it is also about food cultures and traditional practices, which determine food patterns. When communities are allowed to engage in the deliberative process, they gain a better understanding about the links between food choices and diets, health, and environmental factors such as biodiversity effects and food security. Such an understanding means that people are more willing to accept the need for alternatives, as well as to providing informed consent for a more sustainable future direction.

Finally, government and governance require greater foresight for their development. The results of the survey point to national government as the only stakeholder perceived to have a weaker role by 2050. Since perception can easily become reality in democratic governance, this calls for changes to more traditional approaches, and thus, for government to begin embodying the types of sustainable changes envisaged for the future. Such changes involve greater transparency in governance, added clarity on the different roles that stakeholders have and how they participate, as well as a critical distinction between public mandates and private decision-making. A foresighted and orderly approach to governance would include a deliberative process for the evolution of public governance, as well as the design of new institutions that recognise an evolving society and stronger sustainability governance.

Author Contributions: Conceptualization, C.M.; data curation, C.M. and R.K.; formal analysis, C.M. and R.K.; funding acquisition, L.A.; investigation, C.M. and R.K.; methodology, C.M. and R.K.; project administration, L.A.; supervision, L.A.; visualization, R.K.; writing-original draft, C.M.; writing-review and editing, R.K. and L.A. All authors have read and agreed to the published version of the manuscript.

Funding: This study was funded by the Environment Research and Technology Development Fund (S-16-3) of the Environment Restoration and Conservation Agency, Japan and the 10-Year Framework of Programmes on Sustainable Consumption and Production (10YFP).

Acknowledgments: The authors are grateful to the editors and anonymous reviewers for their valuable comments on earlier versions of the manuscript. 
Conflicts of Interest: The author declares no conflict of interest.

\section{References}

1. United Nations. Paris Agreement; United Nations: Paris, France, 2015.

2. IPCC. Global Waming of $1.5^{\circ} \mathrm{C}$ : An IPCC Special Report on the Impacts of Global Warming of $1.5^{\circ} \mathrm{C}$ above Pre-Industrial Levels and Related Global Greenhouse Gas Emission Pathways, in the Context of Strengthening the Global Response to the Threat of Climate Change; The Intergovernmental Panel on Climate Change: Geneva, Switzerland, 2018.

3. The Government of Japan. The Long-Term Strategy under the Paris Agreement; The Government of Japan: Tokyo, Japan, 2019.

4. United Nations. Transforming Our World: The 2030 Agenda for Sustainale Development, United Nations Department of Economic and Social Affairs; United Nations: New York, NY, USA, 2015.

5. Dubois, G.; Sovacool, B.; Aall, C.; Nilsson, M.; Barbier, C.; Herrmann, A.; Bruyère, S.; Andersson, C.; Skold, B.; Nadaud, F.; et al. Energy Research \& Social Science It starts at home? Climate policies targeting household consumption and behavioral decisions are key to low-carbon futures. Energy Res. Soc. Sci. 2019, 52, $144-158$. [CrossRef]

6. Koide, R.; Lettenmeier, M.; Kojima, S.; Toivio, V.; Amellina, A. Carbon Footprints and Consumer Lifestyles: An Analysis of Lifestyle Factors and Gap Analysis by Consumer Segment in Japan. Sustainability 2019, 11, 5983. [CrossRef]

7. Lettenmeier, M.; Liedtke, C.; Rohn, H. Eight Tons of Material Footprint-Suggestion for a Resource Cap for Household Consumption in Finland. Resources 2014, 3, 488-515. [CrossRef]

8. Mao, C.; Koide, R.; Brem, A.; Akenji, L. Technological Forecasting \& Social Change Technology foresight for social good: Social implications of technological innovation by 2050 from a Global Expert Survey. Technol. Forecast. Soc. Chang. 2020, 153, 119914. [CrossRef]

9. Solem, E. Foresight in government: A necessary but rare component. Futures Can. 1986, 8, 3-7.

10. Nazarko, J.; Radziszewski, P.; Dȩbkowska, K.; Ejdys, J.; Gudanowska, A.; Halicka, K.; Kilon, J.; Kononiuk, A.; Kowalski, K.J.; Król, J.B.; et al. Foresight Study of Road Pavement Technologies. Procedia Eng. 2015, 122, 129-136. [CrossRef]

11. Dreyer, I.; Stang, G. Foresight in governments-practices and trends around the world. Yearb. Eur. Secur. 2013, 1368, 7-32.

12. Costanza, R.; Alperovitz, G.; Daly, H.; Farley, J.; Franco, C.; Jackson, T.; Kubiszewski, I.; Schor, J.; Victor, P. Building a sustainable and desirable economy-in-society-in-nature. In State of the World 2013: Is Sustainability Still Possible? Island Press: Washington, DC, USA, 2013; pp. 126-142. [CrossRef]

13. Dumitru, A.; Mira, R.G. Green Lifestyles, Alternative Models and Upscaling Regional Sustainability-GLAMURS: Description of Work. Glamus, Supporting Green Lifestyles; University of A Coruna: A Coruna, Spain, 2017.

14. Mao, C.; Koide, R.; Akenji, L. Society and Lifestyles in 2050: Insights from a Global Survey of Experts; Institute for Global Environmental Strategies: Hayama, Japan, 2019.

15. Habegger, B. Strategic foresight in public policy: Reviewing the experiences of the UK, Singapore, and the Netherlands. Futures 2010, 42, 49-58. [CrossRef]

16. Akenji, L.; Chen, H. A Framework for Shaping Sustainable Lifestyles; United Nations Environment Programme: Paris, France, 2016.

17. Stiglitz, J.E.; Sen, A.; Fitoussi, J.-P. Report by the Commission on the Measurement of Economic Performance and Social Progress; Commission on the Measurement of Economic Performance and Social Progress: Paris, France, 2009.

18. Wiedenhofer, D.; Smetschka, B.; Akenji, L.; Jalas, M.; Haberl, H. Household time use, carbon footprints, and urban form: A review of the potential contributions of everyday living to the $1.5^{\circ} \mathrm{C}$ climate target. Curr. Opin. Environ. Sustain. 2018, 30, 7-17. [CrossRef]

19. Teubler, J.; Buhl, J.; Lettenmeier, M.; Grei, K.; Liedtke, C. A Household's Burden-The Embodied Resource Use of Household Equipment in Germany. Ecol. Econ. 2018, 146, 96-105. [CrossRef]

20. Tukker, A.; Cohen, M.J.; Hubacek, K.; Mont, O. The Impacts of household consumption and options for change. J. Ind. Ecol. 2010, 14, 13-30. [CrossRef] 
21. Calof, J.; Smith, J. Firesight impacts from around the world: A special issue. Foresight 2012, 14, 5-14. [CrossRef]

22. Martin, B.R. The origins of the concept of "foresight" in science and technology: An insider's perspective. Technol. Forecast. Soc. Chang. 2010, 77, 1438-1447. [CrossRef]

23. Cespedes, Q.M.; Martin, D.P. Technology foresight in traditional Bolivian sectors: Innovation traps and temporal unfit between ecosystems and institutions. Technol. Forecast. Soc. Chang. 2017, 119, 280-293. [CrossRef]

24. Nemeth, B.; Dew, N.; Augier, M. Understanding some pitfalls in the strategic foresight processes: The case of the Hungarian Ministry of Defense. Futures 2018, 101, 92-102. [CrossRef]

25. Weber, K.M.; Gudowsky, N.; Aichholzer, G. Foresight and technology assessment for the Austrian parliament-Finding new ways of debating the future of industry 4.0. Futures 2018, 109, 240-251. [CrossRef]

26. Kuosa, T. Practising strategic foreisght in government: The cases of Finland, Singaper and European Union; S. Rajaratnam School of International Studies: Singapore, 2011.

27. Grethe, H.; Dembele, A.; Duman, N. How to Feed the World's Growing Billions: Understanding FAO World Food Projections and Their Implications; WWF Germany: Berlin, Germany, 2011.

28. Bourgeois, R.; Penunia, E.; Bisht, S.; Boruk, D. Technological Forecasting \& Social Change Foresight for all: Co-elaborative scenario building and empowerment. Technol. Forecast. Soc. Chang. 2017, 124, 178-188. [CrossRef]

29. Ahlqvist, T.; Rhisiart, M. Emerging pathways for critical futures research: Changing contexts and impacts of social theory. Futures 2015, 71, 91-104. [CrossRef]

30. Amanatidou, E. Foresight process impacts: Beyond any official targets, foresight is bound to serve democracy. Futures 2017, 85, 1-13. [CrossRef]

31. Jegou, F.; Gouache, C. Envisioning as an enabling tool for social empowerment and sustainable democracy. In Responsible Living: Concepts, Education and Future Perspectives; Thoresen, V., Didham, R., Klein, J., Doyle, D., Eds.; Springer: Cham, Switzerland, 2015.

32. Poli, R. The implicit future orientation of the capability approach. Futures 2015, 71, 105-113. [CrossRef]

33. Konnola, T.; Brummer, V.; Salo, A. Diversity in foresight: Insights from the fostering of innovation ideas. Technol. Forecast. Soc. Chang. 2007, 74, 608-626. [CrossRef]

34. Institute for Global Environmental Strategies, Aalto University, D-mat Ltd. 1.5-Degree Lifestyles: Targets and Options for Reducing Lifestyle Carbon Footprints; Technical Report; Institute for Global Environmental Strategies: Hayama, Japan, 2017.

35. Rhisiart, M.; Störmer, E.; Daheim, C. From foresight to impact? The 2030 Future of Work scenarios. Technol. Forecast. Soc. Chang. 2017, 124, 203-213. [CrossRef]

36. Slaughter, R.A. The Foresight Principle: Cultural Recovery in the 21st Century; Adamantine Press: London, UK, 1995.

(C) 2020 by the authors. Licensee MDPI, Basel, Switzerland. This article is an open access article distributed under the terms and conditions of the Creative Commons Attribution (CC BY) license (http://creativecommons.org/licenses/by/4.0/). 